terral of a line from each other; they are attached by a small peduncle to the cellular membrane, and have scarcely any union to the muscular fibre."

These bodies could not be discovered in the inflamed muscle about the joint, or in asy other structure belonging to the articulation,

A portion of one of the muscles was for many years preserved by spirits, during which period the vesicular character continued to be well exhibited.

I remember the concern $I$ felt at my incapacity to explain this phenomenon to the to the pupils who were present. I could only say it was a new one to me, and all I could do was to hazard the conjecture that the vesicles existed before the injury was received, and I concluded they were parasitic, bearing a close resemblance to those lymphy cysts which they had lately seen in a case of hydatid ascites.

\section{ELECTRICITY IN TETANUS.}

\section{To the Editor of The LanceT.}

Sin:-In your notice of the letter of $\mathbf{M}$. Matteucci (June 2nd) to the Institute of France, on the application of electricity for the cure of tetanus, you seem not to be aware that the same thing has been attempted in London, and with the happiest results. But while I highly admire M. Matteucci's truly philosophic method of using this subtle agent for the cure of one of the most intractable of diseases, in justice to myself I claim the priority of its successful application in the above-named disease, and beg to refer to a case published by me in The LANCET for $1827-8$, p. 72 . At that time I was not aware of the experiments of Volta on the extremities of the frog, nor was I aided by any other inductive reasoning than that, as the old routine of remedies had hitherto almost jnvariably failed, it would be useless to persevere with them. Pathology was dark as chaos itself, and as the leading features of the malady appeared to indicate a highly morbid condition of the servous system, it was therefore not improbable that any agent which was capable of producing a new action, might thereby counteract those convulsive and agonising throes which, in traumatic tetanus, the medical practitioner has had too often to witness with regret. Accordingly electricity was tried, and the ellect was im. mediate and striking. The whole muscular system instantly became relaxed, the jaws opened, and the patient was at once con: vinced of its curative power.

It is worthy of remark, that the electric fuid was found to be perfectly inert until the system was first brought fully under the effect of opium; by persevering in this me- thod the patient rapidly recovered. I am, Sir,your obedient servant,

Old Kent-road, July 9, 1838

J. TAYLOR.

\section{RECLAMATION OF MR. STACK.}

\section{To the Editor of The Lancet.}

SrR :-Being very much pained and surprised at hearing that in THE LANCET of last week it was stated that $I$ admitted in the course of my evidence in the Queen's Bench, June 30th, that at some period of my life I was a private soldier and a servant, I beg leave to assure you, that no such assertion was then or there made or insinuated, much less admitted by me.

I have only to add, Sir, but that the respectability and known independence of your publication forbids the supposition, I must come to the conclusion that THE LANCET had on this occasion lent itself to some cowardly and contemptible enemy of mine. I remain, Sir, your obedient humble servant, P. H. Stack.

Legg's Coffee-house, St. Martin's-lane, July, 1838.

[Our notice of the trial, "The Queen $v$. Mansell and Others," in which the name of Mr. Stack occurs, was condensed from a report in the "Morning Herald." Mr. Stack has assured us that not one of the admissions reported by that journal, as having been made during his cross-examination, were made by him. If this be the case, Mr. Stack, should address himself to the Editor of the "Morning Herald," or to the person who furnished the report to that journal.-ED. L.]

\section{BEETLES IN THE MOUTH.}

Died at Barton-upon-Humber, lately, James Boyers, well-known for many years in Lincolnshire as a noted horsebreaker. No man living perhaps ever experienced so many fractures from accidents with horses, from which causes, probably, he was latterly so reduced as to be a living skeleton, wearing an iron prop to keep his head in position above his shoulders. It is a remarkable fact that about three weeks ago a surgeon was called in to open an abscess in his mouth, when a brood of the common house clock had seated themselves in a cavity of his jaw where an old tooth had been ex. tracted. He was latterly very helpless, and his house being infested with these insects, it is supposed they took possession of their hiding-place when he was asleep.-Lincoln Gazette, May 22.

The Lincoln Mercury of May 25, copied this paragraph as a "Lincolnshire Jonathanism," in consequence of which the surgeon above referred to published the following statement in defence of the "remarkable fact:"- 